\title{
Dinâmica das importações de carne ovina no Brasil: análise dos componentes temporais
}

\section{Dynamics of imports of sheep meat in Brazil: analysis of temporal components}

\author{
João Garibaldi Almeida Viana ${ }^{1 *}$; Mariana Regina Espalter de Moraes²; \\ Josiane Pedroso Dorneles ${ }^{2}$
}

\begin{abstract}
Resumo
A ovinocultura é uma importante atividade pecuária do Brasil. Sua produção se estende pelo território nacional, sendo fonte de renda e subsistência. Pelo lado da demanda, constata-se um aumento do consumo interno, alavancado pelo aumento do poder aquisitivo da população. Para atender a demanda crescente, o Brasil acessa os mercados internacionais do produto por meio de importações. Neste contexto, o trabalho tem por objetivo analisar a dinâmica das importações da carne ovina no Brasil de 2000 a 2012, dando especial atenção às características de tendência e sazonalidade da quantidade importada. Os dados mensais de volume e valor das importações foram coletados a partir do Sistema AliceWeb. A análise estatística dos dados baseou-se no método clássico multiplicativo de séries temporais. Identificou-se uma tendência ascendente de importação de carne ovina, com crescimento anual de $5,09 \%$ no período analisado. Ainda, na quantidade total comercializada, destaca-se a compra de cortes ovinos com osso. Verificou-se um comportamento sazonal na importação de carne ovina, concentrando-se, fundamentalmente, nos meses de final de ano, com volume importado $68 \%$ superior à média da quantidade total. $\mathrm{O}$ principal parceiro comercial do Brasil para o produto é o Uruguai, mercado responsável por, no mínimo, $80 \%$ do volume anual de importação.
\end{abstract}

Palavras-chave: Agronegócio, economia rural, ovinocultura

\begin{abstract}
The sheep production is an important livestock activity in Brazil. Its production stretches away into the country, a source of income and livelihood. On the demand side, there is an increase in domestic consumption, driven by the increased purchasing power of the population. To meet the growing demand, Brazil access international markets through of sheep meat imports. In this context, the work aims to analyze the dynamics of sheep meat imports in Brazil from 2000 to 2012, giving particular attention to the tendency and seasonality of the quantity imported. The data of volume and value of imports were collected from the system AliceWeb. Statistical analysis followed the multiplicative time series model. Identified an upward tendency of sheep meat import, with annual growth of 5.09\% in the period. Still, the total quantity commercialized, there is the purchase of sheep bone cuts. There was the seasonal behavior in the import of sheep meat, focusing primarily in the months of the end of the year, with import volumes $68 \%$ higher than the average of the total amount. The main trading partner of Brazil is the Uruguay, market responsible for at least $80 \%$ of the annual volume of import.
\end{abstract}

Key words: Agribusiness, agricultural economics, sheep raising

\footnotetext{
${ }^{1}$ Prof. Adjunto, Universidade Federal do Pampa, UNIPAMPA, Campus Santana do Livramento, RS. E-mail: joaoviana@unipampa. edu.br

${ }^{2}$ Bacharéis em Ciências Econômicas, UNIPAMPA, Campus Santana do Livramento, RS. E-mail: marianaespalter@gmail.com; josianepdorneles@gmail.com

* Autor para correspondência
} 


\section{Introdução}

A década de 1990 foi caracterizada pelo aumento e difusão de acordos regionais e comerciais entre países de todo o mundo, que tinha como objetivo garantir a troca de especialidades produtivas e elevar sua participação no contexto econômico mundial. A mais importante consequência desse novo cenário foi o fim da fronteira entre políticas domésticas e políticas externas, principalmente a de comércio externo. Assim, desde então, o comércio exterior tem representado um meio pelo qual os países buscam, além de estabelecer uma relação política e econômica, obter uma maior dinamização de seus mercados (THORSTENSEN, 1998).

No caso do Brasil, a intensificação dos acordos comerciais surgiu no âmbito da integração dos mercados na América Latina, onde foram estabelecidos acordos como o MERCOSUL e a Associação Latino Americana de Integração, e, atualmente, o país vem ampliando seus acordos com países de diversas regiões.

Dado a importância do comércio internacional, o Brasil tem buscado estabelecer tais relações com os diversos setores produtivos em que atua, seja por meio das exportações, onde a produção mais dinamizada tende a escoar seus excedentes para outro país, assim como na importação de produtos, a fim de atender suas necessidades de consumo e tecnologias.

No âmbito do agronegócio, as exportações de produtos agrícolas atingiram a cifra recorde de US\$ 81,4 bilhões em 2011, principalmente em função das elevadas cotações internacionais das commodities agrícolas registradas nesse ano, enquanto que as importações agroindustriais no mesmo ano alcançaram US\$ 11,6 bilhões, com elevação de 29,7\% em relação ao valor importado em 2010 (MAPA, 2012).

Neste sentido, evidencia-se a crescente participação brasileira no comércio internacional de alimentos, com destaque para a produção e exportação de carne bovina, suína e de frango. A expectativa é que a produção nacional de carnes suprirá 44,5\% do mercado mundial. Essa estimativa indica que o Brasil manterá sua posição de primeiro exportador mundial de carnes bovina e de frango nos próximos anos (MAPA, 2013).

Em contrapartida, no mercado de carnes do Brasil, a criação de ovinos se encontra em reestruturação. A ovinocultura é uma importante atividade pecuária do Brasil. Sua produção se estende pelo território nacional, sendo fonte de renda e subsistência. No contexto produtivo, o setor ovino emerge como uma alternativa de exploração econômica para médios e pequenos produtores, principalmente pela possibilidade da produção integrada com bovinocultura de corte, bovinocultura de leite, silvicultura, fruticultura e vitivinicultura. A carne ovina, que era considerada um subproduto, consumida apenas nos estabelecimentos rurais ou comercializada de forma desorganizada, passou a assumir uma posição de destaque na atividade (PEREIRA NETO, 2004).

Assim, a carne ovina despontou como principal produtoda atividade, alavancada, fundamentalmente, pelo crescimento do rebanho ovino do nordeste brasileiro (SORIO; RASI, 2010). Os rebanhos começaram a ser explorados economicamente com a introdução de raças especializadas, melhoramento genético e técnicas de manejo que propiciaram a elevação da produtividade em Estados como da Bahia e Ceará. Para Jesus Júnior, Rodrigues e Moraes (2010), destaca-se também um movimento em direção às regiões Centro-Oeste e Norte, comprovado pelo aumento consistente do rebanho ovino, principalmente nos estados de Mato Grosso, Acre, Rondônia e Pará, bem acima da média nacional. Porém, o Rio Grande do Sul mantém seu status de maior Estado produtor de ovinos do Brasil (IBGE/SIDRA, 2011). No entanto, o desafio do setor produtivo, segundo Viana, Revillion e Silveira (2013), reside em criar capacidade de oferta de produtos cárneos ovinos para diferentes mercados, desde nichos altamente especializados à mercados de consumo em massa. 
Na perspectiva da demanda, dados da FAO (2013) evidenciam um crescimento do consumo mundial de carne ovina ${ }^{3}$. Para estudo da FAO (2005), a demanda de carne nos países em desenvolvimento vem sendo impulsionada pelo crescimento demográfico, pela urbanização e pelas variações das preferências alimentares dos consumidores.

O mercado de carne ovina no Brasil, mesmo com um consumo interno baixo em comparação aos demais tipos de carne ${ }^{4}$, apresenta um excesso de demanda, determinando, assim, a necessidade de compra do produto no mercado externo. Dessa forma, segundo Barchet e Freitas (2012), ganham espaço no mercado interno as importações de carne ovina, as quais se apresentam como uma ferramenta para equilibrar o mercado, além de possibilitar aos consumidores uma carne com um preço acessível economicamente.

Neste contexto, o trabalho teve por objetivo analisar a dinâmica das importações da carne ovina no Brasil de 2000 a 2012, dando especial atenção às características de tendência e sazonalidade da quantidade importada. Os resultados buscam compreender a trajetória recente do comércio externo brasileiro de carne ovina, pontuando as principais características e comportamentos desse mercado na última década.

\section{Material e Métodos}

A pesquisa seguiu o método quantitativo, por meio da análise de séries temporais. Foram analisados dados referentes à quantidade de carne ovina importada (quilogramas) pelo Brasil no período de agosto de 1999 a janeiro de 2013. Os dados secundários foram coletados a partir do Sistema de Análise das Informações de Comércio Exterior (AliceWeb) do Ministério do

3 Segundo dados da FAO (2013), a demanda por carne ovina e caprina, no período de 2000 a 2007 cresceu em torno de $5 \%$ no Brasil, $10,45 \%$ na América do Norte, $19 \%$ na África e $23,55 \%$ na Ásia.

4 O consumo de carne ovina no Brasil ainda é restrito, 0,7 quilogramas per capita ano (SILVA, 2002).
Desenvolvimento, Indústria e Comércio Exterior (MDIC, 2013). As variáveis foram segmentadas em três tipos de carne ovina importada (desossada, com osso e carcaça) e na variável quantidade total de carne ovina importada. A análise estatística dos dados baseou-se no método clássico multiplicativo de séries temporais (MORETTIN; TOLOI, 1987; PINDYCK; RUBINFELD, 2005).

$$
Y_{i}=T_{i} \times S_{i} \times C_{i} \times I_{i}
$$

Onde: $\mathrm{T}_{\mathrm{i}}=$ tendência de longo prazo na série; $\mathrm{S}_{\mathrm{i}}=$ componente sazonal/estacional; $\mathrm{C}_{\mathrm{i}}=$ componente cíclica de longo prazo; $\mathrm{I}_{\mathrm{i}}=$ componente irregular ou residual.

No uso do método clássico de séries temporais, privilegiou-seaanálise dos componentes detendência de longo prazo e sazonalidade das importações. Inicialmente, os dados foram submetidos à análise de sazonalidade, por meio do método de ajuste sazonal (PINDYCK; RUBINFELD, 2005) na obtenção de índices estacionais correspondentes a cada mês do ano. Os índices sazonais refletem as flutuações periódicas relativamente regulares que ocorrem dentro de cada período de 12 meses, ano após ano (LEVINE et al., 2011). Com o cálculo dos índices buscou-se analisar as oscilações de curto prazo das importações no período de 2000 a 2012.

Posteriormente, os dados temporais de importações foram preparados para a análise da componente de tendência, a partir da suavização por meio do cálculo de médias móveis centradas de 12 períodos, a fim de extrair a componente sazonal e irregular da série. Para a análise de tendência de longo prazo utilizou-se do método de extrapolação simples que se baseia no desenvolvimento de um modelo de regressão determinístico de séries temporais de uma única equação, denominado de tendência-linear.

A tendência de importações foi estimada por meio de um modelo de regressão linear (equação 
2) e regressão semilogarítmica (equação 3) para análise da taxa de variação mensal.

$$
\begin{aligned}
& Y_{t}=\alpha+\beta t+\varepsilon \\
& \ln Y_{t}=\alpha+\beta t+\varepsilon
\end{aligned}
$$

Onde: $Y_{t}=$ quantidade de carne ovina importada; $\ln Y_{i}=$ logaritmo natural da quantidade importada; $\alpha=$ intercepto; $\beta=$ coeficiente angular; $t=$ tempo da série histórica representado pelo número de meses; $\varepsilon_{\mathrm{i}}=$ resíduo.

A análise de tendência busca verificar um padrão geral ou persistente de longo prazo, ascendente ou descendente (LEVINE, et al., 2011). Os modelos de tendência foram estimados para cada um dos tipos de carne ovina importada pelo Brasil, bem como pela variável de importação agregada. A existência ou não de tendência declinante ou ascendente foi verificada através do teste de hipótese $t$-student, a um nível máximo de 5\% de significância. As hipóteses testadas nesta etapa da pesquisa foram:

a) Hipótese nula $\left(\mathrm{H}_{\mathrm{o}}\right)$ : Não há tendência de elevação ou de queda na quantidade de carne ovina importada pelo Brasil no período de 2000 a 2012;

b) Hipótese alternativa $\left(\mathrm{H}_{1}\right)$ : Há tendência de elevação ou de queda na quantidade de carne ovina importada pelo Brasil no período de 2000 a 2012.

$\mathrm{Na}$ regressão semilog, a interpretação dos coeficientes foi em forma de taxa de variação mensal, conforme a equação 4 , baseada na denotação de Wooldridge (2011), o que possibilita a comparação do comportamento das importações brasileiras, conforme o tipo de produto e quantidade agregada.

$$
\% \Delta Y_{t} \approx(100 \cdot \beta) \Delta t
$$

Ainda, de forma complementar, foi analisada a quilograma) dos diferentes tipos de carne ovina, a partir de representação gráfica e de medidas descritivas. Por fim, identificaram-se os principais mercados fornecedores de carne ovina para o Brasil, indicando sua participação no volume total importado do período.

Portanto, o método clássico de séries temporais permitiu a análise das importações do setor ovino brasileiro, desmembrando as componentes estruturais desse mercado externo e possibilitando a compreensão da trajetória econômica destas relações comerciais.

\section{Resultados e Discussão}

O mercado de carne ovina no Brasil vem crescendo. O aumento de renda da população, a ampliação da comercialização da carne ovina em nichos e seu papel como produto substituto no mercado de carnes são fatores que estimulam a demanda pelo produto.

Sob o ponto de vista produtivo, a ovinocultura enfrentou uma grave crise de na década de 1990, afetando o maior estado produtor: o Rio Grande do Sul. Os preços da lã no mercado internacional caíram drasticamente, desestimulando a produção. Os efeitos da crise se estenderam ao longo das últimas décadas, reduzindo o rebanho ovino gaúcho. Por outro lado, a ovinocultura apresentou consistente crescimento nas regiões Nordeste e Centro Oeste do Brasil, elevando a oferta de carne ovina nessas regiões. Neste contexto, o mercado de carne ovina do Brasil se configura com um consumo maior do que a produção interna, necessitando de importações do produto para atingir um equilíbrio entre oferta e demanda do produto no cenário nacional.

Dessa forma, analisar o comportamento das importações brasileiras ao longo da última década possibilita compreender a dinâmica deste mercado, pontuando suas principais características e trajetória de longo prazo. A Figura 1 apresenta o 
comportamento mensal das importações de carne ovina do Brasil (quilogramas), bem como suas médias móveis e tendência no período de Janeiro de 2000 a Julho de 2012.

Figura 1. Tendência, médias móveis e importações de carne ovina do Brasil ao longo do período de Janeiro de 2000 a Julho de 2012.

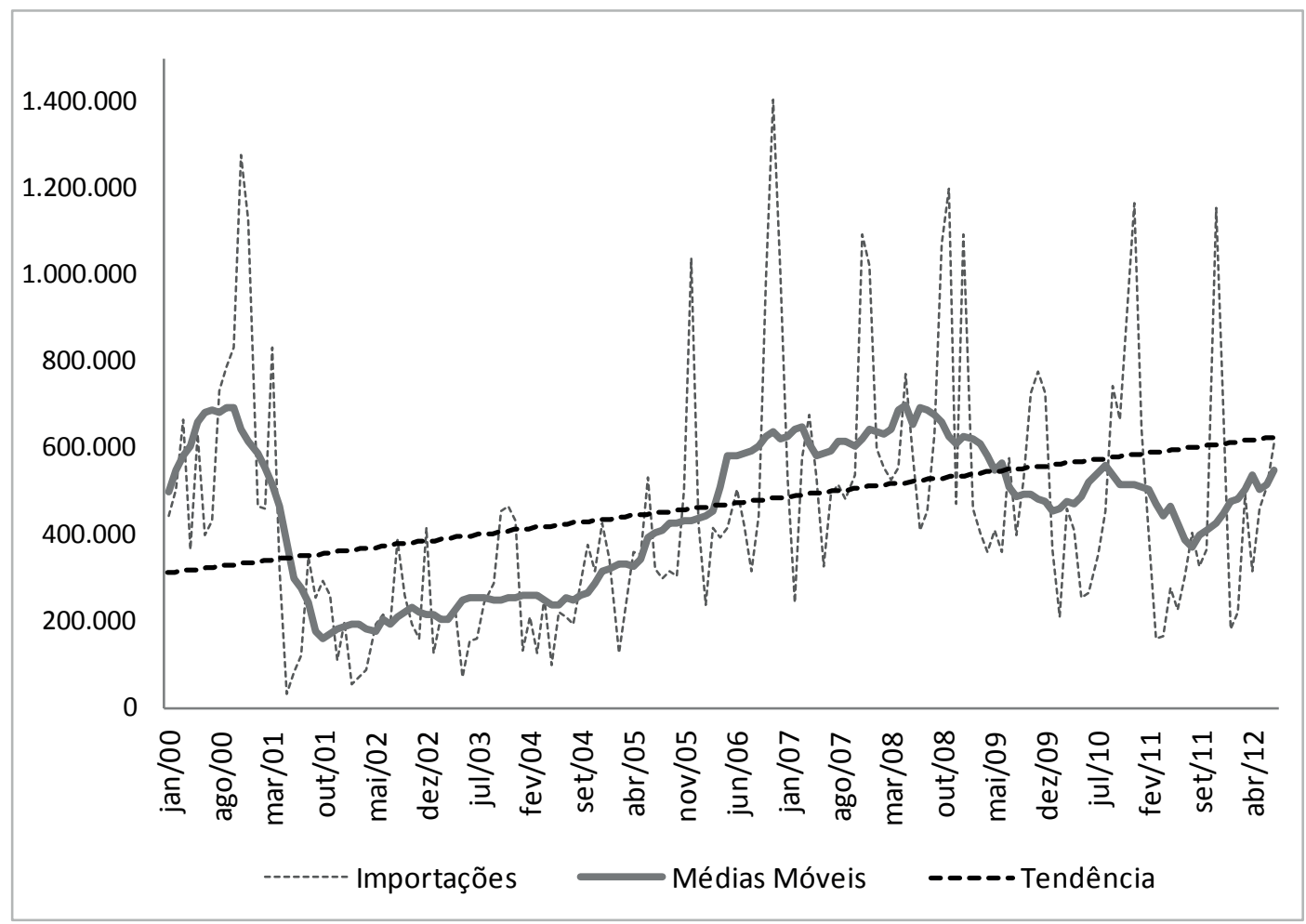

Fonte: Elaboração dos autores.

Visualiza-se uma tendência ascendente de importação de carne ovina ao longo do período analisado, representada pela inclinação positiva da reta de tendência. A partir do coeficiente angular estimado, infere-se que as importações de carne ovina do Brasil apresentaram um crescimento mensal médio de 1.391,66 quilogramas no período $(\mathrm{P}<0,01)$. Ao analisar o coeficiente da regressão log-linear, identifica-se um crescimento anual de $5,09 \%$ na quantidade importada $(\mathrm{P}<0,01)$, indicando que, apesar das oscilações de curto prazo, as importações totais do setor apresentaram uma elevação consistente nos últimos 12 anos.

As importações totais de carne ovina são formadas pelas importações de distintos tipos de carne. Os três principais produtos ovinos importados são as carnes desossadas, carnes (cortes) com osso e a carcaça. Dessa forma, cabe analisar o comportamento das importações dos tipos específicos de carne ovina, a fim de compreender a dinâmica de comercialização dentro dos diferentes produtos importados pela indústria ovina do Brasil.

A Tabela 1 apresenta os coeficientes da regressão linear e semilogarítmica de tendência para a importação de diferentes tipos de carne ovina pelo Brasil no período de Janeiro de 2000 a Julho de 2012. 
Tabela 1. Coeficientes da regressão linear e semilogarítmica de tendência para a importação de carne ovina (desossada, cortes com osso e carcaça) do Brasil.

\begin{tabular}{lcccc}
\hline \multicolumn{1}{c}{ Modelos } & Intercepto $(\boldsymbol{\alpha})$ & Coef. Angular $(\boldsymbol{\beta})$ & $\boldsymbol{t}$ calculado & Valor $\boldsymbol{p}$-fisher \\
\hline Desossada & & & & \\
$\mathrm{Yt}$ & $46.771,59$ & $-217,96$ & $-6,55$ & 0,000 \\
$\ln \mathrm{Yt}$ & 10,57 & $-0,0054$ & $-6,27$ & 0,000 \\
\hline Carne com osso & & & & \\
$\mathrm{Yt}$ & $230.928,50$ & $2.282,68$ & 8,301 & 0,000 \\
$\ln \mathrm{Yt}$ & 12,23 & 0,0072 & 8,255 & 0,000 \\
\hline Carcaça & & & \\
$\mathrm{Yt}$ & $34.144,10$ & 13,69 & 0,238 & 0,8116 \\
$\ln \mathrm{Yt}$ & 9,73 & 0,0044 & 2,675 & 0,0083 \\
\hline
\end{tabular}

Fonte: Elaboração dos autores.

Evidenciam-se, através dos interceptos e coeficientes angulares, que os cortes de carne ovina com osso são os tipos de carne com o maior volume importado no período. Ainda, a carne com osso apresentou maior crescimento no período, com taxa de variação positiva media de $8,64 \%$ ao ano $(\mathrm{P}<0,01)$ no período analisado.

Ressalta-se que as carnes desossadas tiveram um decréscimo significativo $(\mathrm{P}<0,01)$ nas importações brasileiras de 2000 a 2012, reduzindo seu volume importado numa taxa de $6,48 \%$ ao ano. Já a forma de importação de carne ovina por meio de carcaça não apresentou tendência de longo prazo significativa no modelo de regressão linear, indicando uma estabilidade de volume importado.

Estes dados indicam que o Brasil firma-se como um importador de carne ovina no cenário internacional, com volume temporal crescente, fundamentalmente de produtos cárneos com osso. Podem-se destacar os cortes de costela, pernil e paleta ovina dentro desta categoria de importação.
O comportamento importador se justifica pela falta de produto no mercado interno. $\mathrm{O}$ crescimento das importações na última década indica a presença de um mercado dinâmico, com um consumo menos instável no longo prazo, determinando oportunidades para o sistema produtivo nacional.

Em contrapartida, Barreto Neto (2010) afirma que as cadeias substitutas à carne ovina são mais eficazes, estabelecidas no mercado com economias de escala, curvas de experiência, identificação pelo consumidor e acesso preferencial aos canais de distribuição. Assim, a falta de competitividade da cadeia ovina reforça a necessidade de importações, a fim de minimizar os gargalos existentes no processo de produção e abate.

Após uma análise de longo prazo, cabe verificar as oscilações de curto prazo no volume importado de carne ovina no Brasil, ou seja, a sazonalidade das importações ao longo dos meses do ano. A Figura 2 apresenta a sazonalidade mensal da quantidade importada de carne ovina pelo Brasil no período de Janeiro de 2000 a Julho de 2012. 
Figura 2. Sazonalidade da quantidade importada de carne ovina pelo Brasil no período de Janeiro de 2000 a Julho de 2012.

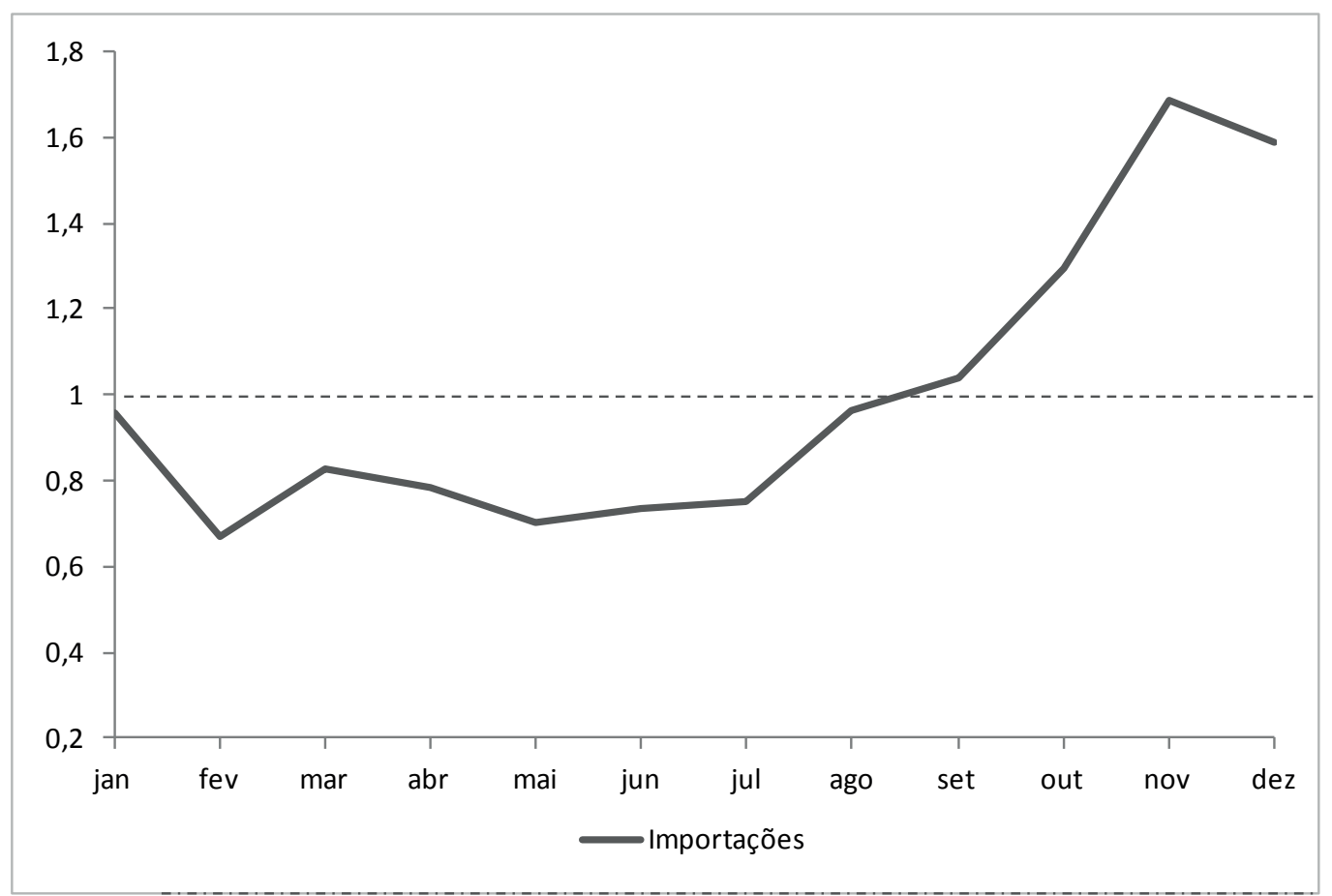

Fonte: Elaboração dos autores.

O índice sazonal equivalente ao valor um (1) refere-se a média mensal da quantidade de carne ovina importada no período. Assim, valores que se situam abaixo ou acima desse índice referem-se aos meses com importação abaixo e acima da média do período, respectivamente.

Nota-se que durante os primeiros oito meses do ano o Brasil apresenta uma redução das importações de carne ovina, com volume importado abaixo da média do período. Apenas a partir do mês de setembro que as importações são retomadas em um volume maior, alcançando seu pico no mês de novembro.

Nos primeiros meses do ano as importações brasileiras ficam em torno de $20 \%$ abaixo da média do volume comercializado no período. As importações alcançam seu pico nos meses de final de ano, com volume importado $68 \%$ superior à média do período. Este comportamento configura uma sazonalidade marcante do mercado internacional de carne ovina do Brasil, indicando uma característica de demanda irregular e concentrada no curto prazo.

Pode-se atribuir esse comportamento sazonal de importação aos costumes do consumo da carne ovina no Brasil. O maior consumo está atrelado as festas de final de ano, conforme hábitos religiosos e de confraternização do período. Isso determina um crescimento da demanda interna do produto nestes meses. Como a oferta doméstica é incapaz de satisfazer a procura ascendente, as indústrias recorrem ao mercado externo, aumentando o volume importado para satisfazer a demanda do mercado nacional.

Nota-se que novembro é o mês de pico de importação, a fim de suprir o consumo crescente a partir de dezembro. Durante os primeiros meses do ano, a demanda se desloca, mantendo, como característica do mercado, um consumo de nicho, reduzindo assim a quantidade procurada, levando a uma redução do volume importado. Esse ciclo 
sazonal se repete ao longo dos anos, com diferentes intensidades, determinando assim a importância das importações de carne ovina para a manutenção da demanda nacional nos meses de novembro e dezembro.

O principal parceiro comercial do Brasil no mercado externo da carne ovina é o Uruguai. $\mathrm{O}$ país se destaca na produção pecuária, sendo um importante exportador de carnes no mercado internacional. Devido à proximidade geográfica e a qualidade da carne produzida, o Uruguai se posiciona como o principal ofertante do volume importado pelo Brasil na última década. A Figura 3 apresenta o volume total importado de carne ovina, o volume importado do Uruguai e a participação da oferta uruguaia no total importado pelo Brasil de 2000 a 2012.

Constata-se que a carne ovina proveniente do Uruguai representa, no mínimo, em torno de $80 \%$ do volume total importado no período. Nota-se uma oscilação da participação do mercado uruguaio, no entanto, o país mantém-se como principal país exportador para o mercado brasileiro. Durante os anos de 2003 a 2008 o Uruguai manteve uma parcela superior a $90 \%$ do volume de carne ovina importada pelo Brasil.

Figura 3. Comparativo entre importações de carne ovina total e importações provenientes do Uruguai no Brasil de 2000 a 2012.

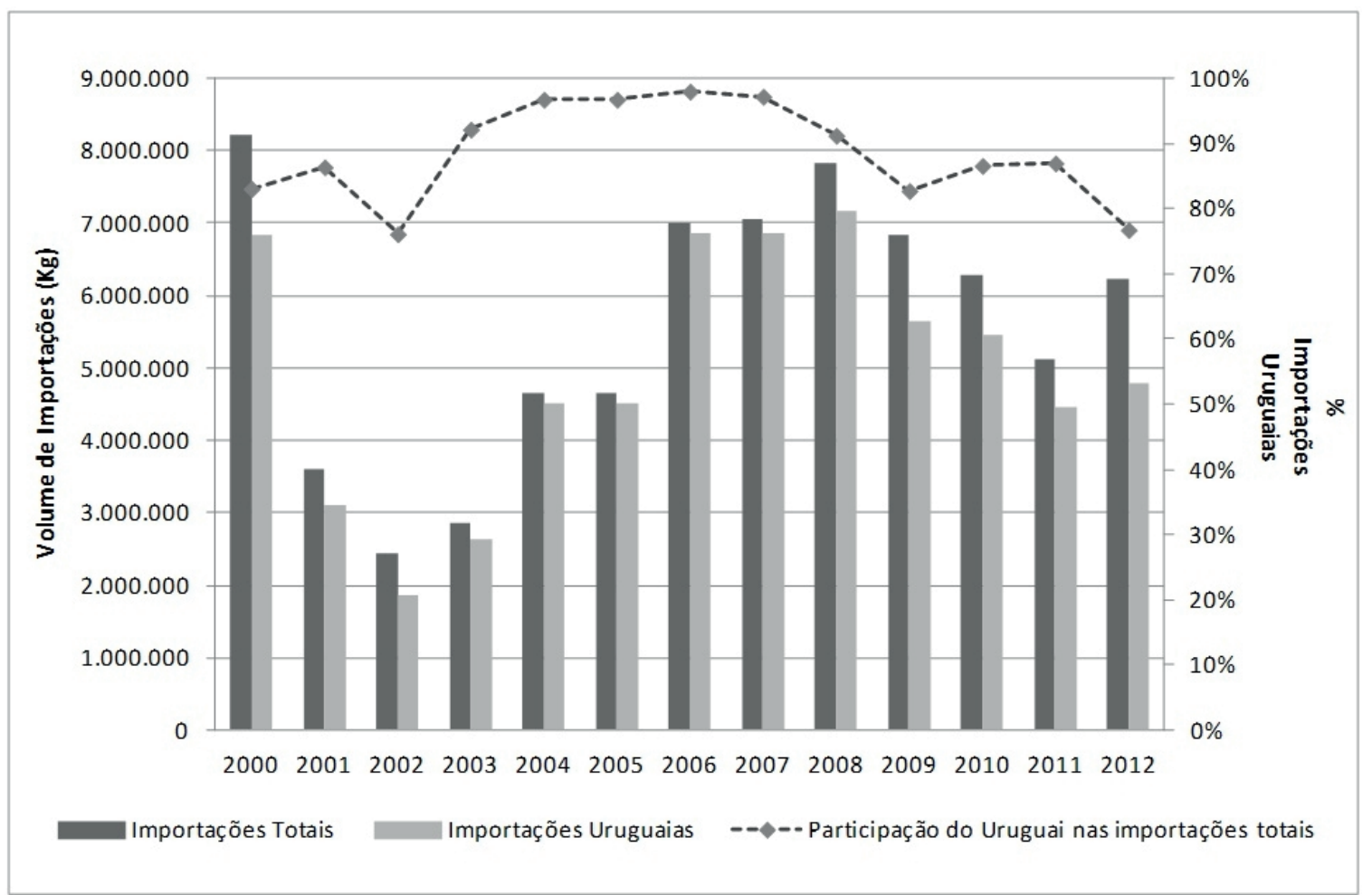

Fonte: Elaboração dos autores.

Assim, o país vizinho se posiciona como Já o mercado brasileiro torna-se dependente principal exportador de carne ovina para o da produção uruguaia para suprir sua demanda Brasil, sendo um importante mercado para a interna, indicando uma dependência dessa relação comercialização do seu excedente de produção. comercial para o equilíbrio do mercado. Nesta 
perspectiva, Barreto Neto (2010) projeta que a capacidade de crescimento da produção uruguaia será limitada, não acompanhando um possível aumento do consumo interno brasileiro, ocasionado uma rigidez de oferta e retendo a ampliação de mercado.

A Figura 4 apresenta o comportamento dos preços de importação (dólares por quilograma) dos diferentes tipos de carne ovina. Os dados estão expostos de forma suavizada (médias móveis), ou seja, desconsiderando os efeitos sazonais de curto prazo.

Em uma análise geral, verifica-se que de 2000 a 2007 os preços mensais de importação permaneceram praticamente estáveis, apenas com oscilações de curto prazo e sem valorização significativa. A partir de 2008, observou-se o aumento dos preços da carne ovina, indicando um comportamento de elevação do produto no mercado internacional. Pode-se explicar esse fato pelo crescimento da demanda mundial e a possível característica de oferta inelástica do produto. Ainda, fatores internos dos sistemas de produção uruguaios, como redução da produção e o avanço da agricultura de grãos sobre áreas pecuárias podem ter afetado a oferta, e consequentemente os preços do produto. Tendo o Uruguai significativa parcela do volume importado, estas mudanças podem ter influenciado a elevação dos preços de importação nos últimos anos.

Figura 4. Comportamento dos preços mensais dos diferentes tipos de carne ovina importada pelo Brasil de 2000 a 2012.

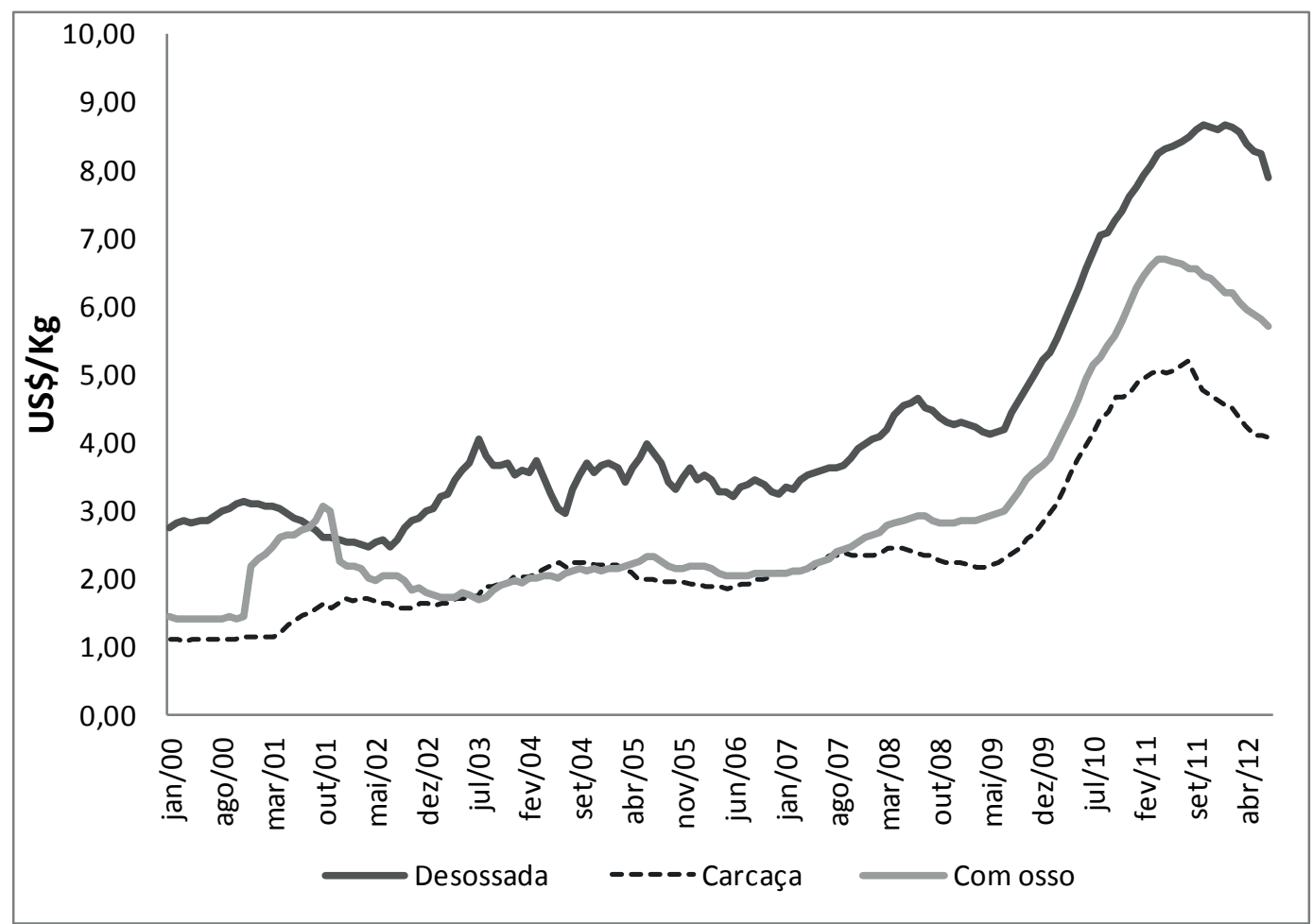

Fonte: Elaboração dos autores.

Ao analisar os preços de importação dos diferentes tipos de carne ovina, destaca-se que as carnes desossadas apresentam valorização superior, chegando a valores próximos a US\$9,00/ quilograma importado. Nesta categoria enquadramse carnes nobres, com alto valor comercial, porém 
com baixa participação no volume total importado pelo Brasil.

A carcaça ovina e as carnes com osso apresentavam preços similares no inicio do período, contudo, a partir de 2008, as carnes com osso apresentaram valorização superior, atingindo um valor médio de US\$ 6,00/kg. Nos últimos meses de 2012 registra-se uma redução dos preços de importação, indicando a existência da reversão de um ciclo recente de alta de preços.

Portanto, as recentes mudanças socioeconômicas no Brasil estimularam o mercado de carne ovina. A demanda em crescimento estimulou a indústria ao acesso de mercados externos em busca de produto para o mercado doméstico. As importações de carne ovina apresentaram uma tendência de crescimento no período de 2000 a 2012, consolidando o Brasil como um importante comprador no mercado internacional. A produção brasileira ainda não é capaz de abastecer a expansão da demanda de seu mercado interno, contrastando com sua liderança em produção e potencial exportador das carnes bovina, suína e de frango.

\section{Agradecimentos}

Ao CNPq e FAPERGS pela concessão de bolsas de iniciação científica ao projeto de pesquisa.

\section{Referências}

BARCHET, I.; FREITAS, C. A. Integração de preços entre o Rio Grande do Sul, Uruguai, Brasil e Austrália nos mercados da carne ovina e da lã. Espacios, Caracas, v. 33, n. 7, p. 5, 2012. Disponível em: <http://www. revistaespacios.com/a12v33n07/12330705.html>. Acesso em: 05 jan. 2013.

FOOD AND AGRICULTURE ORGANIZATION - FAO. Estatísticas - FAOSTAT. Roma: FAO, 2013. Disponível em: <http://faostat.fao.org/>. Acesso em: 5 jan. 2013.

Perspectivas agrícolas 2005-2014. OCDEFAO, Roma, 2005. Disponível em: <http://www.fao.org/ docrep/008/y9492s/y9492s00.htm> Acesso em: 10 out. 2006.
JESUS JÚNIOR, C. de.; RODRIGUES, L. S.; MORAES, V. E. G. de. Ovinocaprinocultura de corte: a convivência dos extremos. BNDES Setorial, Rio de Janeiro, v. 31, p. 281-320, 2010.

LEVINE, D. M.; STEPHAN, D.; BERENSON, M.; KREHBIEL, T. Estatística: teoria e aplicações. Rio de Janeiro: LTC, 2011. 778 p.

MINISTÉRIO DA AGRICULTURA, PECUÁRIA E ABASTECIMENTO - MAPA. Comércio exterior da agropecuária brasileira: principais produtos e mercados. Brasília: Ministério da Agricultura, Pecuária e Abastecimento, Secretaria de Relações Internacionais do Agronegócio, 2012. 132 p.

Temas: exportação. Brasília: MAPA, 2013. Disponível em: <http://www.agricultura.gov.br/>. Acesso em: 10 ago. 2013.

MINISTÉRIO DO DESENVOLVIMENTO, INDÚSTRIA E COMÉRCIO EXTERIOR - MDIC. Sistema de Análise das Informações de Comércio Exterior - ALICEWEB. Brasília: MDIC, 2013. Disponível em: $<$ http://aliceweb2.mdic.gov.br/>. Acesso em: 10 jan. 2013.

MORETTIN, P. A.; TOLOI, C. M. Séries temporais. São Paulo: Atual, 1987. 438 p.

BARRETO NETO, A. D. Posicionamento estratégico do setor de carnes de caprinos e ovinos no mercado de carnes brasileiro. Tecnologia e Ciência Agropecuária, João Pessoa, v. 4, n. 4, p. 81-85, 2010.

PEREIRA NETO, O. A. Gerenciamento e capacitação da cadeia da ovinocultura. In: (Org.). Práticas em ovinocultura: ferramentas para o sucesso. Porto Alegre: SENAR/RS, 2004. p. 1-8.

PINDYCK, D. L.; RUBINFELD, R. S. Econometria: modelos e previsões. Rio de Janeiro: Campus, 2005. 726 p.

SILVA, R. R. da. O agronegócio brasileiro da carne caprina e ovina. Salvador: R. R. da Silva, 2002. 111 p.

SISTEMA IBGE DE RECUPERAÇÃO AUTOMÁTICA - IBGE/SIDRA. Banco de dados agregados - SIDRA. Temas: Pecuária. Brasília: IBGE, 2011. Disponível em: $<$ http://www.sidra.ibge.gov.br/>. Acesso em: 2 abr. 2011.

SORIO, A.; RASI, L. Ovinocultura e abate clandestino: um problema fiscal ou uma solução de mercado? Revista de Política Agrícola, ano 19, n. 1, p. 71-83, 2010.

THORSTENSEN, V. A OMC - Organização Mundial do Comércio e as negociações sobre investimentos e concorrência. Revista Brasileira de Política Internacional, Rio de Janeiro, v. 41, n. 1, p. 57-89, 1998. 
VIANA, J. G. A.; REVILLION, J. P. P.; SILVEIRA, V. C. P. Alternativa de estruturação da cadeia de valor da ovinocultura no Rio Grande do Sul. Revista Brasileira de Gestão e Desenvolvimento Regional, Taubaté, v. 9, n. 1, p. 187-210, 2013.
WOOLDRIDGE, J. M. Introdução à econometria: uma abordagem moderna. São Paulo: Cengage Learning, $2011.725 \mathrm{p}$. 
